\title{
THE CHANGING AETIOLOGY OF ERYTHEMA NODOSUM IN CHILDREN*
}

\author{
BY \\ JOHN LORBER \\ From the Children's Hospital, Sheffield
}

(RECEIVED FOR PUBLICATION SEPTEMBER 9, 1957)

In his Bradshaw Lecture for 1944, Professor Bruce Perry (Perry, 1944) reviewed the historical aspects of the aetiology of erythema nodosum and later Doxiadis gave a more detailed account in his monograph on the subject (Doxiadis, 1951). It has been shown that erythema nodosum is a hypersensitivity reaction and the main triggers which elicit this reaction are certain bacterial and fungal infections. The relative importance of the various aetiological agents is influenced by geographical and racial factors as well as by the age of the patient. Their importance may also vary from time to time. Erythema nodosum was often in the past thought to be a manifestation of rheumatic fever, but this theory has long been disproved. In this country, tuberculosis and beta-haemolytic streptococcal infections are the only known important factors in children.

In recent years, only two large series of cases have been published in Great Britain and both of these emphasized the overwhelming importance of recent tuberculous infection. Perry found that of 67 children with erythema nodosum seen in the Bristol region $50(75 \%)$ were tuberculin positive and 29 $(43 \%)$ showed evidence of active primary tuberculosis. Only 11 children had a clear-cut history of pharyngitis; nine of these were tuberculin negative and skin tests showed that four were sensitive to streptococcal mucoproteins. The incidence of tuberculous infection was even higher in Doxiadis' (1949) 100 children who were seen in Newcastleupon-Tyne and in Sheffield between 1947 and 1949. All his patients were tuberculin tested and $88 \%$ were positive, and $59(67 \%)$ showed evidence of active tuberculous infection. Tuberculous complications developed within three months after the appearance of the erythema nodosum in eight children. A possible streptococcal aetiology has not been excluded for Doxiadis' patients, as tests

\footnotetext{
* Based on a paper delivered to the Paediatric Section of the Royal Society of Medicine on April 26, 1957.
}

for evidence of recent streptococcal infection were not performed. It must be remembered, however, that in those days it was much easier to demonstrate tuberculous infection than streptococcal infection by laboratory means.

\section{Present Investigation}

Material. In view of the recent considerable decline in the incidence of childhood tuberculosis in our community (Lorber, 1953) it seemed of interest to review the cases of erythema nodosum in children seen in Sheffield in more recent years. For this purpose, the records of all the 89 children under 15 years of age who were found to have erythema nodosum and who attended the Children's Hospital, Sheffield, during a period of six years from January 1, 1951, to December 31, 1956, were used. Of these, 40 were under the care of Dr. T. Colver. In addition I obtained permission to include cases seen by Dr. R. R. Gordon of the City General Hospital, Sheffield, and by Dr. H. R. Vickers and Dr. I. B. Sneddon of the Department of Dermatology, the Royal Infirmary, Sheffield. These sources added a further 16 cases for study making a total of 105 . No further cases have been found after searching the records of the various Sheffield Hospitals and of the Chest Clinic.

Age and Sex Incidence. Erythema nodosum was seen in four children under 2 years of age. There were three peak years with 12 cases at 2 years, 17 cases at 9 years and 11 cases at 10 years. Otherwise, the frequency of the condition was very similar at each year of life, with an average of six cases (Fig. 1). Twenty-seven $(26 \%)$ children were under 5 years of age, $42(40 \%)$ were between 5 and 10 years of age and $36(34 \%)$ were 10 to 15 years of age (Table 1).

There were 48 boys $(46 \%)$ and 57 girls $(54 \%)$. There was an interesting and progressive gradient. 
in sex incidence in different age groups (Table 1). Under 5 years of age there were more boys than girls

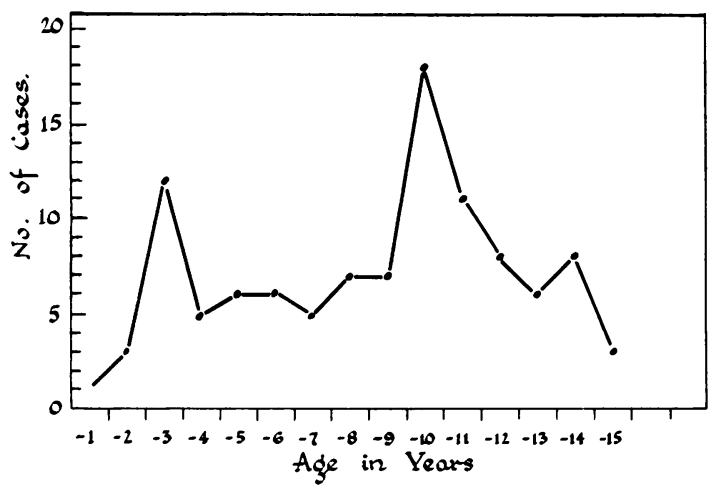

Fig. 1.-Age distribution of erythema nodosum.

TABLE 1

AGE AND SEX INCIDENCE

ERYTHEMA NODOSUM IN SHEFFIELD INVESTIGATION, 1951-56

\begin{tabular}{c|c|cc|cc}
\hline \multirow{2}{*}{ Age in Years } & & Total & Females & \multicolumn{2}{|c}{ Males } \\
\cline { 1 - 5 } & Number & $\%$ & Number & $\%$ \\
\hline-10 & 27 & 10 & 37 & 17 & 63 \\
-15 & 42 & 23 & 55 & 19 & 45 \\
\cline { 1 - 5 } Adults & 56 & 24 & 67 & 12 & 33 \\
\hline All ages & 55 & 52 & 94 & 3 & 6 \\
\hline
\end{tabular}

( 17 boys to 10 girls), between 5 and 10 years of age boys were a little less often affected (19 boys to 23 girls) and between 10 and 15 years there were twice as many girls as boys ( 12 boys to 24 girls).

In 55 adult patients seen by Dr. Vickers and Dr. Sneddon during the same period $52(94 \%)$ were women.

\section{Aetiology}

Tuberculosis. All children were tuberculin tested and a radiograph of the chest was obtained. The tuberculin tests used were the jelly test (without flour paper) and the Mantoux test in varying strengths from 1 to 100 T.U. old tuberculin $(1 / 10,000-1 / 100)$.
A positive skin test was found in 65 children $(62 \%)$ as a result of natural infection. Five other children were also tuberculin positive but these had recently been vaccinated with B.C.G. and form another group. Thirty-five children $(33 \%)$ were tuberculin negative (Table 2 ).

TABLE 2

TUBERCULIN TEST REACTIONS IN CHILDREN WITH ERYTHEMA NODOSUM

\begin{tabular}{|c|c|c|}
\hline Tuberculin Test Reaction & Number & $\%$ \\
\hline $\begin{array}{l}\text { Positive } \\
\text { Positive (B.C.G. vaccinated) } \\
\text { Negative }\end{array}$ & $\begin{array}{r}65 \\
5 \\
35\end{array}$ & $\begin{array}{r}62 \\
5 \\
33\end{array}$ \\
\hline All cases & 105 & 100 \\
\hline
\end{tabular}

There was a decreasing incidence of tuberculous infection during the six years of this study. Whereas in 1951 to $1953,73 \%$ of 49 children were tuberculin positive as a result of natural infection, in 1954 to 1956 this proportion fell to $51 \%$ of 56 cases. There was also a fall in the absolute number of tuberculin positive cases from 36 in 1951 to 1953 to 29 in 1954 to 1956 (Table 3).

TABLE 3

INCIDENCE OF TUBERCULOUS INFECTION IN CHILDREN WITH ERYTHEMA NODOSUM

\begin{tabular}{|c|c|c|c|c|c|}
\hline \multirow[b]{2}{*}{ Year } & \multirow[b]{2}{*}{$\begin{array}{l}\text { Number } \\
\text { of Cases }\end{array}$} & \multicolumn{2}{|c|}{ Tuberculin Positive } & \multicolumn{2}{|c|}{ Active Tuberculosis } \\
\hline & & Number & $\%$ & Number & $\%$ \\
\hline $1947-49^{*}$ & 100 & 88 & 88 & 59 & 59 \\
\hline$\overline{1951-53}$ & 49 & 36 & 73 & 27 & 55 \\
\hline $1954-56$ & 57 & 29 & 51 & 19 & 34 \\
\hline
\end{tabular}

* Doxiadis, 1949.

The incidence of tuberculous infection was practically the same in boys and girls $(62 \%)$. Tuberculosis, however, was much commoner in younger than in older children. Of 29 children aged 2 to 5 years, $25(86 \%)$ were tuberculin positive; of 52 under 9 years of age $37(71 \%)$ and of 53 of 9 years or more only $28(53 \%)$ were tuberculin positive (Table 4).

TABLE 4

INCIDENCE OF TUBERCULOSIS IN CHILDREN WITH ERYTHEMA NODOSUM ACCORDING TO AGE AND SEX

\begin{tabular}{|c|c|c|c|c|c|c|c|c|c|c|}
\hline & \multicolumn{5}{|c|}{ 0-8 Years } & \multicolumn{5}{|c|}{ 9-14 Years } \\
\hline & \multirow[t]{2}{*}{ All Cases } & \multicolumn{2}{|c|}{ Tuberculin Positive } & \multicolumn{2}{|c|}{ Active Tuberculosis } & \multirow[t]{2}{*}{ All Cases } & \multicolumn{2}{|c|}{ Tuberculin Positive } & \multicolumn{2}{|c|}{ Active Tuberculosis } \\
\hline & & Number & $\%$ & Number & $\%$ & & Number & $\%$ & Number & $\%$ \\
\hline Boys & 30 & 21 & 70 & 17 & 57 & 18 & 9 & 50 & 8 & 44 \\
\hline Girls & 22 & 16 & 73 & 13 & 60 & 35 & 19 & 54 & 8 & 23 \\
\hline Total & 52 & 37 & 71 & 30 & 58 & 53 & 28 & 53 & 16 & 30 \\
\hline
\end{tabular}


Children with Active Primary Tuberculosis. A positive tuberculin reaction does not necessarily indicate that the erythema nodosum was due to the tuberculous infection, unless tuberculin conversion coincided in time with the eruption and other possible causes were excluded. Unfortunately, in most cases there was no record of the tuberculin status before the skin eruption. It was possible, however, to divide the 65 tuberculin positive children into two groups: in $46(43 \%)$ there was clinical and radiological evidence of a recent and active tuberculous process, and in the remaining 19 the only evidence of the tuberculous infection was the positive skin test.

The proportion of children with active primary tuberculosis was $55 \%$ in 1951 to 1953 (27 of 49) and only $34 \%$ (19 of 56) in 1954 to 1956 (Table 3). As might be expected, younger children with a positive skin test more often had an active tuberculous lesion. In children under 9 years of age $58 \%$ had active lesions as compared with $30 \%$ of all children aged 9 years or more. Among $\mathbf{3 5}$ girls aged 9 years or more only eight or $23 \%$ had an active tuberculous infection (Table 4). In this group there was a big difference between the incidence of active tuberculosis in the two sexes.

All the 46 children ( 25 boys and 21 girls) with definite active primary tuberculosis had non-calcified primary complexes or enlargement of the hilar lymph nodes in radiographs of the chest. In no case was the hilar enlargement bilateral. In 18 of those who had been followed up for a sufficient period calcifications were subsequently demonstrated. Significant contact with an active case of tuberculosis was either already known or was found to have occurred immediately prior to the onset of the erythema nodosum in 22 cases. In five cases, tubercle bacilli were cultured from gastric washings. This is a minimal figure, as children were often not admitted to hospital and gastric washings were not a routine procedure. Ten of the 46 are known to have developed important tuberculous complications within nine months of the eruption. These were tuberculous meningitis in three, bronchopneumonia in one, arthritis of the hip in one, pleural effusion in three and phlyctenular conjunctivitis in two (Table 5).

Children with Inactive Tuberculosis. It is not possible to calculate precisely the expected incidence of positive tuberculin reactors in this group of 105 children based on the incidence in the general child population, as the information is not sufficient and the numbers are relatively small. It is likely, however, that the incidence of $18 \%$ who showed a positive tuberculin reaction as the only evidence of infection corresponds fairly well to that in the general child population. Seven of $52(13 \%)$ were under 9 years of age, and 12 of $53(23 \%)$ were over 9 years of age. There was only one child in this group who had definite enlargement of the hilar lymph nodes but he was known to be tuberculin positive 18 months earlier. None of these 19 children are known to have developed tuberculous illness of any type during the period of observation.

B.C.G. Vaccinated Children. Five children who gave a positive tuberculin reaction had been vaccinated with B.C.G. before the onset of the erythema nodosum. One of these, a boy of 14, was vaccinated nine months earlier at school and he converted two months later. His illness followed a sore throat and although his throat swab was negative when he was first seen, the antistreptolysin-O titre was 600 units. A radiograph of the chest was normal. The B.C.G. vaccination was clearly not responsible for his eruption, which was probably due to streptococcal infection.

In the other four vaccinated children the eruption occurred at about the time of tuberculin conversion, but an additional factor was present in three of these, so that the B.C.G. vaccination was not necessarily responsible for the attack. The father of one had active pulmonary tuberculosis and this 18-month-old child was not segregated from him during the period of vaccination. The child developed erythema nodosum only two weeks after vaccination. He then had a normal radiograph of the chest, but two years later a further radiograph showed a shadow consistent with a primary tuberculous complex. This child may well have had a recent virulent tuberculous infection which led to his erythema nodosum.

TABle 5

TUBERCULOUS COMPLICATIONS IN 46 CHILDREN WITH ACTIVE PRIMARY TUBERCULOSIS

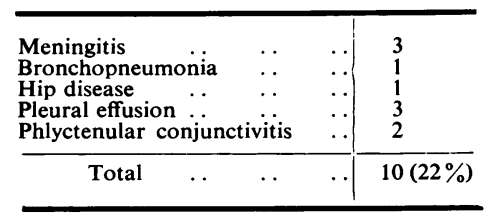

Two 13-year-old girls had been vaccinated at school. One had already had an attack of erythema nodosum four years earlier and the fresh attack was preceded by a severe sore throat. When first seen her throat swab was negative, but an A.S.O. titre was not performed. She had a typical fresh B.C.G. lesion, and a radiograph of the chest was 
normal. The other girl was vaccinated only three weeks before the erythema nodosum, but she already had a good B.C.G. lesion and gave a positive reaction to 10 units of O.T. A radiograph of the chest was negative. She did have a sore throat a week before the onset of the erythema nodosum, but her throat swab when first seen was negative. The A.S.O. titre was 200 units. The eruption cleared completely, but two weeks later a fresh extensive eruption developed without a preceding sore throat. This time beta-haemolytic streptococci were present in her throat swab. In these two girls either the B.C.G. vaccination or a streptococcal infection or both might well have been responsible for the eruption.

Finally, an infant aged 10 months had a mild eruption of erythema nodosum six weeks after vaccination without any other additional feature. This is the only child in whom B.C.G. was the only known predisposing factor, but streptococcal infection was not excluded by laboratory evidence.

Streptococcal Infection. Of the 35 patients whose tuberculin tests and radiographs were negative at the time of their erythema nodosum, 17 had a sore throat within two weeks before the eruption. Throat swabs were taken at the time of the child's first visit in 15 children, including 11 with preceding sore throats, and beta-haemolytic streptococci were grown in four. In addition, an elevation of the A.S.O. titre was found in six children whose throat swabs were negative or in whom swabs were not taken (titres of 200, 450,600,800, 900 and 2,000 units). A recent beta-haemolytic streptococcal infection was therefore demonstrated in ten of these 35 (Table 6). In 19 children in this group no investigations were undertaken to detect such infections. Among 11 children from whom were obtained both throat swabs for culture and blood for A.S.O. titre, there were only two who gave a negative reaction to both tests.

Unfortunately, in most of the tuberculous cases no further investigations were carried out after a positive tuberculin test and other evidence of active tuberculosis was found. Nevertheless, among the 65 tuberculin positive children the eruption was preceded by a severe sore throat in 15, and Lancefield group A beta-haemolytic streptococci were cultured from throat swabs in four of these. Another child had an A.S.O. titre of 500 units. As no throat swab was taken from 45 children and the antistreptolysin-O titre was only estimated in one, the five proven cases of concurrent streptococcal infections represent a minimal figure. Four of the five had an active tuberculous lesion.
Among the 105 children there were, therefore, $35(33 \%)$ who complained of a preceding sore throat; beta-haemolytic streptococci were found in their throat swabs in nine and a significant elevation of their A.S.O. titre was also found in nine patients. The total with proven streptococcal infection was 17 $(16 \%)$ (Table 6).

TABLE 6

INCIDENCE OF STREPTOCOCCAL INFECTION IN CHILDREN WITH ERYTHEMA NODOSUM

\begin{tabular}{|c|c|c|c|}
\hline Type of Case & Total & Pharyngitis & $\begin{array}{c}\text { Positive Throat Swab or } \\
\text { Elevated A.S.O. Titre* }\end{array}$ \\
\hline $\begin{array}{l}\text { Tuberculous } \\
\text { B.C.G. . } \\
\text { Non-tuberculous }\end{array}$ & $\begin{array}{r}65 \\
5 \\
35\end{array}$ & $\begin{array}{r}15 \\
3 \\
17\end{array}$ & $\begin{array}{r}5 \\
2 \\
10\end{array}$ \\
\hline Total & 105 & 35 & 17 \\
\hline
\end{tabular}

* 200 units or more.

Rheumatic Fever. Only one child had coexistent rheumatic fever. This boy of 12 developed erythema nodosum and rheumatic fever with carditis following a streptococcal tonsillitis.

Other Diseases. In no child were other associated diseases detected, e.g., sarcoid or meningococcaemia.

Drugs. None of the children received sulphathiazole and no clear evidence is available that drugs played a part in provoking the eruption in any case.

Familial Factors. More than one case of erythema nodosum occurred in three families. In one, a girl of 11 years and a boy of 8 years had erythema nodosum at about the same time following sore throats. Both of these were known to have been tuberculin positive 18 months earlier. In the second the mother developed erythema nodosum before her 2-year-old boy. The boy had an active tuberculous infection which was probably contracted from a tuberculous neighbour.

More interesting is the history of the third family in which three children were affected in the course of six years. This is the only true example of familial susceptibility to erythema nodosum in this series.

The three children, twin brothers and a cousin, lived in the same house. All three were persistently tuberculin negative. One twin developed erythema nodosum at the age of 6 , in 1950. The next episode occurred in January, 1953, when the second twin had erythema nodosum following a sore throat. $\mathrm{He}$ had beta-haemolytic streptococci in his throat. The first twin then had a second attack in December, 1954, without any apparent predisposing cause. Finally, their first cousin, a girl of 9 years, had erythema nodosum a further 15 months 
later. She, too, had a proven beta-haemolytic streptococcal throat infection.

Relapses. Six children $(5 \%)$ had a second attack after the eruption of the first attack had completely faded. Two children had their first attack before 1951 and four during the six years of this study. In three, the second attack occurred between three and five years after the first one. In the three others this happened within four weeks of the first crop. In only one child was active tuberculosis detected at the time of the first attack, but even she had a preceding sore throat. In none of the other cases did tuberculosis play a part, except that two had been vaccinated with B.C.G. not long before their second attack. It is of interest, however, that the twins quoted above, one of whom had two attacks, were subsequently vaccinated with B.C.G. without subsequent erythema nodosum.

\section{Discussion}

It is legitimate to conclude from these findings that although tuberculosis is still a very important aetiological factor in erythema nodosum in children, its importance is steadily decreasing. In the last three years little more than half the children had a positive tuberculin reaction and only one-third had active tuberculosis.

Tuberculosis was a far more important aetiological factor in young children among whom $71 \%$ had a positive skin test and most of these had active primary tuberculosis. These figures are in contrast with children over 9 years of whom only $30 \%$ had active primary tuberculosis.

As B.C.G. vaccinations are increasing in number, we shall have to think of it among the possible causes when confronted with a case of erythema nodosum.

We shall not know the true incidence of streptococcal aetiology until all cases are investigated routinely by throat swabs and the estimation of A.S.O. titres. When we do this we shall probably find many cases of erythema nodosum in which multiple factors operate. This was shown to some extent by the figures which have been presented. The concept of mixed infection or complex aetiology has previously been elaborated by Westergren (1945).

Holmdahl (1950) found in a series of 657 cases that the prognosis of primary tuberculosis was much worse in children with than in those without erythema nodosum. Our smaller series fully confirms his findings. It appears reasonable, therefore, to prescribe a course of treatment with isoniazid plus streptomycin or P.A.S. for children who show evidence of an active primary tuberculosis associated with erythema nodosum.

\section{Summary}

In a consecutive series of 105 children with erythema nodosum seen in Sheffield between January 1951 and December 1956, $65(62 \%)$ were tuberculin positive as a result of tuberculous infection, five cases followed B.C.G. vaccination, and $35(33 \%)$ were tuberculin negative.

There was a progressively falling proportion of children with a positive tuberculin reaction. Out of 49 children seen in 1951 to $1953,73 \%$, and out of 56 seen in 1954 to 1956 only $51 \%$ were tuberculin positive. An active primary tuberculous lesion was seen in 46 children $(43 \%)$ in the whole series. The proportion was $55 \%$ in children seen during 1951 to 1953 and $34 \%$ in 1954 to 1956 . Ten of the 46 children developed various forms of tuberculous diseases (apart from the erythema nodosum and the primary complex) during observation. In 19 children $(18 \%)$ the only evidence of tuberculosis was a positive skin test.

Five children developed erythema nodosum after B.C.G. vaccination, and in four this occurred at the time of tuberculin conversion. Nevertheless, additional tuberculous or streptococcal infections were present in three of them.

Among 35 tuberculin negative children, 17 complained of a preceding pharyngitis and in ten laboratory evidence of a beta-haemolytic streptococcal infection was obtained; in 19 children no investigations were performed to prove a possible streptococcal aetiology. Such investigations were even less commonly performed in the 65 tuberculin positive children. Nevertheless the eruption was preceded by a sore throat in 15 and streptococcal infection was demonstrated in five. Among the 105 cases there were altogether 17 with a proven streptococcal infection.

Relapse of the erythema nodosum occurred in six cases and multiple cases occurred in three families.

I wish to thank Professor R. S. Illingworth for his criticism; Dr. T. Colver, Dr. R. R. Gordon, Dr. I. B. Sneddon and Dr. H. R. Vickers for permission to study their cases and the many family physicians who referred their patients to us.

\section{REFERENCES}

Doxiadis, S. A. (1949). Brit. med. J., 2, 844.

(1951). Medicine (Baltimore), 30, 283

Holmdahl, K. (1950). Acta tuberc. scand., Suppl. 22.

Lorber, J.'(1953). Brit. med. J., 2, 1122.

Perry, C. B. (1944). Ibid., 2, 843.

Westergren, A. (1945). Nord. Med., 25, 312 